Revista Signos

$2010 / 43$

Número Especial

Monográfico $\mathrm{N}^{\circ} 2$

295-309

\title{
La interpretación interactiva de los textos a través de las tertulias literarias dialógicas
}

\author{
Cristina Pulido \\ Universidad de Barcelona \\ España
}

\author{
Brigita Zepa \\ Baltic Institute of Social Sciences \\ Letonia
}

Resumen: En este artículo se reflexiona sobre los actos comunicativos dialógicos en el proceso de interpretación interactiva del texto y sus implicaciones en la transformación social. Contradiciendo los análisis estructuralistas como el de Bourdieu, en el que la interpretación de los textos está ligada al habitus de la persona lectora, autores como Bakhtin defienden una interpretación dialógica de los textos. Una de las actuaciones de éxito analizadas en el proyecto de investigación INCLUD-ED es la experiencia de las tertulias literarias dialógicas, protagonizada tanto por personas adultas o por niñas y niños de familias de bajos ingresos que comparten la lectura de clásicos de la literatura universal. Las personas demuestran a través de sus actos comunicativos dialógicos que no existe una única interpretación experta, superando las interacciones de poder de entornos académicos tradicionales.

Palabras Clave: Actos comunicativos dialógicos, habitus, interacciones dialógicas.

Recibido: 20-IV-2010 Aceptado: 9-VII-2010
Correspondencia: Cristina Pulido (cristinapulido@ub.edu). Departamento de Teoría Sociológica, Filosofía del Derecho y Metodología de las Ciencias Sociales. Facultad de Economía y Empresa, Universidad de Barcelona. Diagonal Nord, Diagonal 690, 08034 Barcelona, España. 


\title{
The interactive interpretation of texts through dialogic literary gatherings
}

\begin{abstract}
This article is a reflection on the dialogic communicative acts in the process of interactive text interpretation and their effects on social transformation. Contrary to structuralist analysis, such as Bourdieu's, in which text interpretation is linked to the habitus of the reader, authors like Bakhtin defend the dialogic interpretation of the texts. One of the successful actions analysed in the INCLUDED research project is the experience of the dialogic literary gatherings, where a group of adults or a group of children from families with low SES share the reading of classic works from universal literature. People show -through their dialogic communicative acts- that there is not only one expert interpretation, thus overcoming the interaction of power in traditional academic contexts.
\end{abstract}

Key Words: Dialogic communicative acts, habitus, dialogic interactions.

\section{INTRODUCCIÓN}

Ante la postura de la interpretación de los textos clásicos universales se han identificado dos enfoques que mantienen su vigencia. El primer enfoque recoge la tradición teórica estructuralista que limita la interpretación al conocimiento experto (Bourdieu, 2000). El segundo enfoque parte de orientaciones dialógicas de los textos (Bathkin, 1981; Flecha, 2000) que incluyen la diversidad de voces en la interpretación de los mismos.

Socialmente existe una tendencia a infravalorar las capacidades lingüísticas de las personas no académicas o con niveles de estudios primarios. En cambio la riqueza del desarrollo lingüístico se ha asociado a las personas con estudios superiores y pertenecientes a clases sociales medias altas (Bourdieu, 2000). Partiendo de esta contribución, diríamos que ante una misma obra (literaria, pictórica, etc.) se prestaría más atención a la opinión que generaría una persona académica que a una persona sin estudios. Pero, no es la única tendencia en la sociedad.

En este artículo mostramos cómo la concepción de los actos comunicativos dialógicos (Searle \& Soler, 2004; CREA 2006-2008), y contribuciones teóricas clave como la concepción de la gramática universal de Chomsky (1985) o la dialogicidad de Bakhtin (1981), contradicen las teorías estructuralistas que vinculan la capacidad de lenguaje y discurso crítico a ciertos grupos sociales (Bourdieu, 2000). Dichas teorías son la base de la actuación de éxito, las tertulias literarias dialógicas, donde se demuestra que la interpretación de los textos no es monopolio de unos pocos expertos sino el resultado del diálogo entre personas diversas. Las personas participantes transforman sus conocimientos culturales a través de las interacciones dialógicas que se generan y el uso del lenguaje que realizan. Tanto el desarrollo lingüístico como la elaboración de discursos críticos profundos son resultado de la predominancia de actos comunicativos dialógicos en estas tertulias. 
El artículo se estructura en un primer apartado de exposición del marco teórico, un segundo apartado que argumenta cómo los actos comunicativos dialógicos favorecen la interpretación dialógica e interactiva de los textos, y las transformaciones que se generan a partir de ello. Para finalizar elaboraremos un apartado que expone cómo las tertulias basadas en estos actos comunicativos dialógicos desmonopolizan el conocimiento experto (Beck, 2006).

\section{Marco teórico}

La teoría estructuralista de Bourdieu argumenta que el habitus de la persona condiciona sus gustos e incluso su capacidad para acceder a ciertos conocimientos propios de la élite cultural. En su obra 'La distinción' (Bourdieu, 2000) expone cómo los gustos culturales dependen del habitus del sujeto; si una persona ha nacido en un entorno cultural de clase alta, sus gustos estarían directamente relacionados con los bienes culturales a que dicho grupo social puede acceder. Consecuentemente y según este autor, las clases populares no acceden ni desarrollan el gusto respecto a estos bienes culturales, ni adquieren los elementos necesarios para interpretar y entender dichas obras.

Así es como en el capítulo 'El placer de la lectura' (Bourdieu, 2000) argumenta, basándose en aportaciones de Proust o Anatole France, cómo la lectura propia de personas eruditas solo puede apreciarse por personas consideradas distinguidas. Aquellas personas que forman parte del vulgo no pueden llegar a apreciar este tipo de arte. Únicamente unos elegidos pueden comprender el verdadero sentido del lenguaje que de ahí se desprende (Bourdieu, 2000: 510):

"El placer cultivado se alimenta de esas referencias cruzadas, que se refuerzan y legitiman mutuamente, produciendo de manera inseparable la fe en el valor de las obras, la "idolatría" que se encuentra en el mismo principio del placer cultivado, y el inimitable encanto que objetivamente ejercen sobre todos los que, poseedores poseídos, pueden entrar en el juego. Incluso en su forma más pura, más libre en apariencia de todo interés "mundano", ese juego es siempre un juego de sociedad (...)"

En otras palabras Bourdieu y Mizraji (1988) en su obra 'Cosas dichas' exponen cómo la lectura de obras clásicas solo puede ser interpretada en su valor por personas eruditas que son aquellas personas capacitadas para interpretar más fielmente la propia lógica de la obra (Bourdieu \& Mizraji, 1988: 124): “Este proceso alcanza su cumplimiento cuando la reinterpretación letrada del lector se aplica a las obras de una tradición letrada y la lógica de la reinterpretación es la misma que la lógica de la cosa interpretada".

El habitus condiciona al sujeto a poder acceder a dichos bienes culturales. Pero ello no signifi- 
ca la imposibilidad de este acceso por partes de grupos sociales de clase popular, si se crean las condiciones necesarias para ello. A continuación se expone algunas de estas condiciones.

La primera condición es valorar las aportaciones de los sujetos, independientemente cual sea su origen sociocultural. Esta valoración se recoge en las aportaciones de autores como Chomsky y Eco.

Chomsky (1985), aportaba cómo la capacidad de lenguaje es innata al ser humano, y que por tanto cualquier sujeto podía desarrollarla y mejorarla continuamente. Todas las personas son capaces de poder interpretar los textos que se proponga y aportar su propia valoración.

Eco $(1979,1992)$ realizó una aportación clave respecto la apertura de la interpretación de las obras. Afirmaba cómo cualquier obra además de contener cierta información objetiva (el sentido de la obra, el propio sentido del autor, las características propias del contexto), también se debía abrir a la interpretación del lector. Y que dicha apertura podía contener diversas lecturas, tantas como posibles lectores de la obra, sin limitarlo al origen sociocultural del lector.

La segunda condición es que la interpretación de los textos se lleve a cabo de una forma interactiva o dialógica, tal y como indican Bakhtin o Flecha.

Bakhtin (1981) argumenta que el texto puede recoger tantas interpretaciones como visiones del mundo tengan los lectores que se acerquen a él. Según Bakhtin la ambigüedad sobre el significado del texto es lo que hace necesario la dialogicidad para ser capaces de crear significados conjuntos. Lejos de asumir que no es posible el entendimiento debido a esta ambigüedad, propone como alternativa una interpretación dialógica de los textos. Incluso enfatiza cómo la interpretación de textos por parte de personas de diferentes culturas promueve una visión más amplia y crítica del texto (Bakhtin, 1986: 7):

“(...) Una significación solo revela su verdadera profundidad a través del contacto con otra significación extraña y distinta: entre ellas se entabla una suerte de diálogo (...). Un diálogo como ese no desemboca en una mezcla o fusión entre ambas. Por el contrario, cada cultura conserva su propia unidad y su totalidad abierta, pero como consecuencia de ese proceso de diálogo intercultural ambas culturas se han enriquecido mutuamente".

Así es cómo las tertulias literarias dialógicas (Flecha, 2000) son un ejemplo de esta interpretación interactiva y dialógica que menciona Bakhtin. A través de ellas, se evidencia que las interacciones dialógicas se dan en espacios donde prevalecen los actos comunicativos dialógicos (Searle \& Soler, 2004). Y como resultado de ello, se consigue una interpretación interactiva que incluye el mismo valor a las aportaciones emitidas por las personas independientemente cual sea su nivel académico. Así pues la tercera condición es la interpretación interactiva depende 
de los actos comunicativos. Solo los actos comunicativos dialógicos aseguran la interpretación dialógica e interactiva que tanto Bakthin como Flecha describen en sus obras.

Desde esta aportación se ofrece un tipo de análisis lingüístico que complementa las teorías anteriormente señaladas e incorpora otros elementos a incluir en el análisis. Como por ejemplo el lenguaje no verbal, el contexto social de la interacción o la responsabilidad weberiana de la comunicación, entre otros.

Una de las características principales de este tipo de actos es que promueven que las interacciones dialógicas predominen sobre las interacciones de poder. Por ello, las tertulias literarias se caracterizan principalmente porque a partir de los actos comunicativos dialógicos que se generan, se va sustituyendo progresivamente las interacciones de poder por las dialógicas, siendo estas últimas las que más predominan en este espacio.

Esta conceptualización permite profundizar en el análisis de los actos comunicativos que se realizan en diversas situaciones sociales, e identificar qué impacto tiene en los sujetos y en sus acciones. En el caso que nos ocupa, la interpretación interactiva de los textos es posible cuanto más se base en actos comunicativos dialógicos.

Por ejemplo, el análisis que se propone, ayuda a distinguir con mayor precisión la diferencia que hay entre algunas de las tertulias literarias basadas en el conocimiento experto y una tertulia literaria dialógica. La principal diferencia que se establece entre ellas hace referencia a los actos comunicativos que se generan. En el primer tipo de tertulia predominan las interacciones de poder en los actos comunicativos que se desarrollan, en cambio en el segundo ejemplo prevalecen las interacciones dialógicas sobre las de poder.

Las tertulias literarias dialógicas basan su comunicación en actos comunicativos dialógicos. Dichos actos se diferencian de los de poder, porque incluyen la sinceridad y el respeto sin coacciones. Impulsan interacciones dialógicas pero teniendo en cuenta que el contexto social y la estructura lleva por sí misma desigualdades que influyen en la comunicación entre los sujetos. Las personas participantes de la tertulia se responsabilizan del resultado del acto comunicativo, no solo dejándolo a su intención como hablantes, sino comprometiéndose con el resultado de la interacción y no solo con la intencionalidad.

Ello podemos ejemplificarlo a través del análisis del acto comunicativo que ejerce la persona moderadora en las tertulias literarias dialógicas. En una tertulia quien ejerce de moderador/a tiene la responsabilidad de crear actos comunicativos dialógicos que promuevan interacciones dialógicas entre los y las participantes. El diálogo que se establece en la tertulia se orienta a establecer este tipo de actos, todas las personas pueden expresar libremente y sin coacciones 
su valoración respecto la obra, además de incluir el respeto a las otras opiniones como criterio básico de su comunicación. Por otro lado, la persona moderadora asume la dimensión de la responsabilidad de la comunicación en su interacción con las personas participantes. Tiene en cuenta que el contexto social incluye desigualdades sociales. En este caso concreto, sabe que su papel como moderador/a le sitúa en una posición de poder frente las otras personas participantes. En lugar de utilizarlo a su favor, parte de esta posición para promover actos comunicativos dialógicos.

Por eso la función de la persona moderadora no es de aleccionar sobre cuál es el análisis y discurso más crítico y profundo sobre la obra. Ello significaría establecer una interacción de poder con las personas participantes de la tertulia (es así porque yo lo digo, por mi posición como moderador o moderadora y persona supuestamente experta). Su función es generar las condiciones necesarias para que predominen los actos comunicativos dialógicos, frente a los de poder.

En el siguiente apartado se ejemplificará cómo es posible dicha interpretación interactiva mediante los actos comunicativos dialógicos, así como ejemplos de transformaciones que se generan a partir de la participación en dichos actos comunicativos.

\section{Las tertulias literarias dialógicas, actuación de éxito en interpretación interactiva de los textos clásicos}

Las tertulias literarias dialógicas se han seleccionado como una de las actuaciones de éxito en el Proyecto Integrado europeo INCLUD-ED (2006-2011). Entre los 6 subproyectos que se llevan a cabo, el proyecto 2 denominado 'European effective educational practices: How is education contributing to overcome or reproduce social exclusion?', ha identificado actuaciones educativas de éxito que disminuyen el fracaso escolar y cuáles lo aumentan. Para ello se realizó una extensa revisión bibliográfica de artículos científicos así como 20 estudios de caso en 6 países europeos. Así es como una de las actuaciones de éxito que emergían fueron las tertulias literarias dialógicas.

Las tertulias literarias dialógicas es una actividad educativa y cultural que se inició en los años 80 en el barrio de la Verneda y que actualmente se está llevando a cabo en diferentes contextos culturales y educativos (Flecha, Soler \& Valls, 2008). Las tertulias han sido objeto de estudio de varias investigaciones y referenciadas en diferentes publicaciones incluidas internacionales, así como reconocidas como práctica educativa innovadora por la Universidad de Harvard en el año $2000^{1}$. 
CONFAPEA ${ }^{2}$ coordina actualmente el proyecto de las Mil y Una Tertulias Literarias Dialógicas por todo el mundo, proyecto que se ideó desde la primera comisión de tertulias creada en el 1999 en Barcelona y coordinada por FACEPA ${ }^{3}$. El objetivo era difundir esta actuación en todos los lugares que fuera posible, puesto que los beneficios tanto de aprendizaje, como sociales y culturales identificados son extraordinarios.

El sueño que se inició hace más de diez años, está creando un impacto en la capacidad crítica y lingüística en colectivos de diferentes edades y contextos sociales. Se está llevando a cabo en diferentes partes del mundo, como en Brasil, España, Chile y Australia, en diferentes marcos institucionales (escuelas, entidades, bibliotecas), con participantes de diferentes edades (personas adultas, niños y niñas, adolescentes), provenientes de diferentes clases sociales y grupos culturales.

El análisis de los actos comunicativos que presentamos a continuación ha sido extraído de personas participantes de tertulias literarias dialógicas. Una de las principales características de estas personas, es que pertenecen a contextos con un bajo nivel socioeconómico, cuyo nivel de estudios es básico o iniciales y/o incluso en procesos de postalfabetización. Según el análisis teórico de Bourdieu (2000) sería inimaginable pensar que estas personas pudieran quedar una vez por semana para discutir obras clásicas de autores como Joyce, Tolstoi, Lorca o Kafka. Pero así lo están haciendo desde hace más de 30 años.

\subsection{Actos comunicativos dialógicos en las tertulias literarias dialógicas}

Como hemos comentado al inicio del artículo, la tendencia social a infravalorar las habilidades interpretativas y lingüísticas de las personas sin estudios es todavía un prejuicio social vigente. Aunque, como hemos visto, haya teorías que pretendan avalarlo como las estructuralistas, existen evidencias teóricas y prácticas que están contradiciendo estos análisis.

Este tipo de tertulias literarias se orientan desde una concepción dialógica, confiando en la capacidad de la agencia humana para transformar las limitaciones que se imponen desde la estructura a través del diálogo. Para ello es necesario partir de lo que se ha comentado en el apartado anterior; la capacidad de lenguaje universal de todas las personas, la interpretación interactiva de los textos como necesaria para ser comprendidos con una mayor profundidad, y la comunicación basada en actos comunicativos dialógicos. En los siguientes párrafos se presenta cómo se desarrollan estos actos comunicativos a través del ejemplo de la tertulia de la Metamorfosis de Kafka.

Una de las características de la tertulia es comentar el texto a través de párrafos escogidos por las personas participantes y establecer el diálogo a partir de ellos, respetando el turno de 
palabra y escuchando cada una de las aportaciones.

Se inicia la tertulia preguntando quién ha traído un párrafo del texto para comentar. "Moderadora: ¿Quién ha seleccionado un párrafo?”. Las participantes que han seleccionado algún párrafo levantan la mano, y la moderadora apunta a las personas. Una vez apuntado, la moderadora da paso a la primera persona para que lea el párrafo. Antonia que es de niveles iniciales, se atreve a leer en voz alta, aunque le cueste, y sus compañeros y compañeras le escuchan con atención. A Antonia ese clima de respeto le anima a superar su vergüenza y después de participar en varias tertulias su nivel de lectura y expresión oral ha mejorado sustancialmente.

Una vez que Antonia lee el párrafo donde Gregorio intenta hacer comprender que está indispuesto y no puede salir de su habitación, y la reacción de sus familiares, Antonia argumenta porqué ha escogido este párrafo:

"He escogido este párrafo porque me ha hecho pensar en cómo a veces las personas pensamos lo que le pasa a la otra persona sin saberlo, sin escuchar o preguntar... empezamos a suponer sin parar a saber qué pasa realmente".

Mientras Antonia habla y expone su comentario, las demás personas participantes la escuchan atentamente. Una vez que Antonia ha acabado, la moderadora pregunta al grupo: “¿Quién quiere hacer una aportación sobre este párrafo?"

Las personas que quieren intervenir levantan la mano y ella apunta el orden de palabras. Seguidamente va dando el turno según este orden, y las personas participantes respetan el turno. Así es cómo surgen contribuciones diversas sobre el mismo párrafo. Unos comentan sobre la incomprensión de la familia ante Gregorio, otras personas enfatizan en cómo el protagonista ha llegado hacia esa situación. Cada aportación va mostrando un matiz diferente y a la vez enriquecedor. Una vez acabado este turno, se da paso a la siguiente persona que había traído un párrafo y se vuelve a realizar la misma operación.

Los y las participantes de la tertulia no buscan el consenso sobre una interpretación única del texto. Pero sí que consensuan cómo deben comunicarse en las tertulias. Por ejemplo, algunos de sus criterios clave son: el respeto por las aportaciones de cualquier persona siempre y cuando no se vulneren los derechos humanos, el clima de escucha y atención, el que nadie monopolice la palabra y animar a aquellas personas que no suelen intervenir. Pero también el lenguaje no verbal es importante, tal y como se incluye en los actos comunicativos dialógicos. Si pudiéramos incluir un vídeo, podríamos ver como cuando alguien está interviniendo, todas las miradas van hacia esa persona, la posición corporal muestra una escucha activa y respetuosa, así como un sentimiento compartido de aprendizaje continuo a través de las aportaciones de los compañeros. 
Todo ello es posible porque los actos comunicativos dialógicos permiten que los sujetos no estén condicionados por coacciones y expresen desde su visión cuál es su aportación al texto. Cada persona aprende de la otra y, conjuntamente, van creando una interpretación interactiva y profunda del texto leído. No hay una persona experta que dirija cuál es la interpretación idónea, sino que la interpretación colectiva es la que más profundiza en la obra. Una persona sola no puede llegar al resultado de la reflexión de treinta personas interpretando conjuntamente.

Participando de estos actos, las personas van transformando su propia visión de la realidad, ampliando su punto de vista a través de las contribuciones que escucha de sus compañeros y compañeras, y también de las suyas propias. Las personas participantes reflexionan sobre 'lo que se habla y cómo se habla en las tertulias', favorece a su vez su implicación en debates públicos u otros movimientos sociales, incluso en sus relaciones personales. Es decir, los actos comunicativos dialógicos que se generan en las tertulias, empoderan a las personas participantes en el ejercicio de una capacidad lingüística y reflexiva crítica en cualquier situación cotidiana que se enfrenten. Trasladan este aprendizaje lingüístico a interacciones que se dan en su realidad cotidiana inmediata.

\subsection{Transformaciones sociales a través de la participación en los actos comunicativos dia- lógicos de las tertulias}

El prejuicio social comentando al inicio de este apartado es una situación que se da frecuentemente en el día a día. En los actos de habla es importante también tener en cuenta el contexto social como estructura que incluye las desigualdades sociales propias de nuestras sociedades. Esto se traduce en relaciones de poder fruto de prejuicios y estereotipos discriminatorios transmitidos por la estructura social. Estas relaciones de poder impregnan los actos comunicativos cotidianos. Así es como por ejemplo encontramos el caso de una mujer no académica participante de la tertulia, María, que al ir a comprar en una tienda la obra Ulises de Joyce, el librero le responde que ese libro no es para ella.

Analizando esta situación comunicativa, vemos cómo el librero, supuesto experto de literatura universal, tiene una concepción determinada de quién puede leer y entender dichas obras clásicas y quién no. Ante la intención de María de adquirir la obra de Joyce, el librero parte de un prejuicio social y genera con María una interacción de poder. El librero actúa desde su situación de experto en obras clásicas y menosprecia la capacidad crítica de María para poder entender dicho libro.

María llevaba tiempo participando en una tertulia literaria dialógica, donde había leído conjuntamente con otras compañeras y compañeros decenas de obras clásicas de la literatura univer- 
sal. Sabía perfectamente que esas obras podían ser leídas y analizadas críticamente por personas como ella. Ante esa interacción de poder, María respondió al librero que esa obra podía ser leída por ella, y por personas como ella, y le explicó lo que hacen en las tertulias literarias dialógicas. Este acto comunicativo dialógico que es la respuesta de esta persona, consiguió que el librero obtuviera información para cuestionar sus prejuicios y rectificara su primera postura entendiendo su equivocación.

María establece una interacción dialógica con el librero, sabiendo que aunque entre ellos siga existiendo una estructura que les sitúa en desigualdad, puede conseguir a través del acto comunicativo dialógico establecer un cambio de percepción por parte del librero. En el momento en que el librero acepta los argumentos establecidos por María, la relación de poder del inicio se torna dialógica.

Las personas no académicas suelen recibir este tipo de interacciones de poder. La comunicación lleva implícita el prejuicio social sobre sus gustos culturales o comprensión al respecto. Este hecho condiciona las interacciones que se establecen con ellos y ellas. Otro ejemplo lo encontramos con Paula y su madre.

Paula, estudiante universitaria, al volver un día a casa ve a su madre que tiene un libro entre sus manos y le dice ¿Mamá qué haces leyendo ese libro? Lola estaba leyendo la 'Odisea' de Homero. El tono con que hace la pregunta Paula, lleva implícito un cuestionamiento de lo que su madre estaba leyendo. El tono marca el prejuicio con que Laura pregunta. Si solo atendemos el sentido literal no entenderíamos esta interpretación. Al incluir el aspecto no verbal en el análisis del acto, identificamos dicho prejuicio. Paula había aprendido que este tipo de obras solo las leían las personas que habían seguido una trayectoria académica, y que su madre, que solo tenía estudios básicos iniciales, no era habitual que leyera obras como las de Homero. Las interacciones aunque sea entre madre e hija, no están exentas de las desigualdades sociales que conlleva la estructura. Pero es a partir de la comunicación que se establece mediante el acto comunicativo dialógico, que se puede identificar y transformar. Por ejemplo Lola cambia la influencia de la estructura al exponer a su hija porqué estaba leyendo ese libro.

Lola explica a su hija que es el libro que están leyendo en la tertulia literaria. Comparte con ella las interacciones que tienen en la tertulia, sobre qué hablan, cómo hablan y el aprendizaje que está adquiriendo. A partir de ese momento, Paula se interesa por las reflexiones que se generan en la tertulia donde participa su madre. Ello provoca un cambio en las conversaciones que tenían habitualmente Paula y Lola. Ya no solo hablan de la comida, la compra o qué sale en la televisión, sino que Paula y Lola transforman la comunicación que habían establecido hasta entonces como madre e hija. Hablan de las obras que lee Lola y las aportaciones que se realizan 
en la tertulia, el sentido de la vida, el papel de la mujer, la solidaridad, el poder, entre otros temas. Su relación se va transformando y van introduciendo tal y cómo sucede en las tertulias, más actos comunicativos dialógicos. Su comunicación se ve enriquecida y profundizada a partir de las interacciones generadas en las tertulias.

En el ámbito universitario también hay ejemplos de ello. Pedro, participante de la tertulia, ha ido a exponer en diferentes clases de la universidad la actividad de las tertulias literarias dialógicas. Habitualmente una de las cuestiones que se preguntan los y las estudiantes universitarios/as es por qué leen los clásicos de la literatura universal y no otro tipos de libros 'más adecuado a su nivel académico'. En esta pregunta también se esconde la interacción de poder resultado de la estructura social y los prejuicios sociales. Esta preconcepción de carácter elitista da por supuesto que el acceso a obras clásicas de la literatura universal está limitado a aquellos colectivos con estudios superiores.

La pregunta de los y las estudiantes es un reflejo de lo que han aprendido en su contexto social, o incluso en la academia, donde se suele afirmar que dichas obras no son leídas por las clases populares. Pedro, que ya está acostumbrado a que le realicen este tipo de preguntas, les expone los argumentos por los que se decide escoger este tipo de obras y no otras. Cuando esta explicación se basa en un acto comunicativo dialógico, basado en la sinceridad y libre de coacciones, los y las estudiantes que integran en su discurso los argumentos de Pedro, transforman su visión sobre las posibilidades y capacidades de estas personas independientemente del contexto social del que vengan.

En las discusiones que tienen en otras clases donde se cuestiona precisamente esta capacidad discursiva crítica de las personas no académicas, ponen en duda la validez de ese argumento. Ante estos actos comunicativos de poder protagonizados por académicos, algunos estudiantes cuestionan ese posicionamiento a través de los argumentos aprendidos con Pedro.

Por otro lado, hay ejemplos de intelectuales que han interactuado con personas participantes de las tertulias, admirados por la capacidad de análisis y discurso crítico que se genera en dichos espacios. Dichos intelectuales teniendo en cuenta su situación de poder, sustituyen las interacciones de poder por interacciones dialógicas. Así es como por ejemplo Miquel Siguán, catedrático lingüístico de reconocido prestigio, y recientemente fallecido en 2010, conoció las tertulias literarias dialógicas en el 2001. A través de la interacción que se estableció entre Miquel Siguán y las personas participantes de la tertulia de la Verneda, escribió un artículo de opinión en La Vanguardia donde afirmaba (Siguán, 2001: 15): 
"Y así se produce una sorprendente paradoja, que las tertulias de antiguos analfabetos, surgidas en medios populares con el propósito de promover el ascenso cultural de los no universitarios a través de la lectura de los clásicos, se constituyen en el mejor ejemplo de lo que los universitarios podrían hacer y no hacen."

¿Qué efecto puede ofrecer estas palabras de Siguán a la audiencia en general de 'La Vanguardia?'. Siguán, catedrático reconocido en el ámbito académico, contribuye al reconocimiento social de las aportaciones de las personas no académicas. Su admiración y valoración elaboradas a partir de las interacciones dialógicas establecidas con las personas participantes en las tertulias, fomenta una mayor reflexión crítica al respecto.

Ello ha sido posible porque el encuentro entre el profesor Siguán y las personas participantes de la tertulia se ha basado en un acto comunicativo dialógico. Si bien, tenían en cuenta que el contexto social generaba una desigualdad de partida (Siguán académico de prestigio y personas no académicas), apuestan porque sus actos comunicativos sean dialógicos. Es decir, basados en la sinceridad y en el acuerdo, y no en la posición de poder que ocupaban unos u otros. Tal y como recogía el profesor Siguán, dicha práctica, debería incorporarse en la academia. Así como también valoraba en su artículo la dinámica de la tertulia como forma de profundizar en la interpretación de los textos (Siguán, 2001).

Los ejemplos expuestos muestran cómo los actos comunicativos dialógicos no solo se establecen en las tertulias literarias dialógicas, sino que las personas participantes de estos espacios, trasladan los actos comunicativos dialógicos que crean en estas tertulias, a sus interacciones diarias. La desmonopolización del conocimiento experto a través de estos actos favorece la transformación social del contexto.

Por tanto, el lenguaje como elemento transformador no se encierra únicamente en la sala donde se realizan estos diálogos, sino que va más allá de sus paredes. Los y las participantes son conscientes que la realidad social todavía predomina las interacciones de poder. Pero a través de su capacidad de lenguaje y como sujetos de transformación, van creando situaciones comunicativas donde predominan las interacciones dialógicas. Aunque tienen en cuenta que no solo depende de ellos y ellas, sino también que sus interlocutores además apuesten por este tipo de interacciones, tal y como hizo Siguán.

\section{CONCLUSIONES}

¿El placer de la lectura es solo para la élite? Tal y como hemos visto al inicio del artículo, Bourdieu (2000) defendía que el placer de la lectura solo podría ser disfrutado por las personas 
eruditas o como recogía en su otra obra ‘Cosas dichas' (1989), únicamente podía ser entendida por las personas letradas.

En contra de ello, en las tertulias literarias dialógicas comprobamos cómo las personas que participan en ellas están apasionadas por la lectura, por las contribuciones que generan en esos espacios y por lo que van creando con su capacidad de lenguaje conjuntamente.

Ante esta realidad podemos analizar ¿Cómo puede conseguir una tertulia convocar a más de cuarenta personas cada semana para interpretar conjuntamente obras de la literatura clásica universal? ¿Cuál es el secreto del éxito de las tertulias literarias dialógicas?

La ilusión que se genera en ellas. El encanto de la comunicación se establece en aquellos espacios donde los actos comunicativos dialógicos predominan por encima de los actos comunicativos de poder, en aquellos espacios donde las interacciones dialógicas son mayores que las interacciones de poder.

El lenguaje que se utiliza en ellas conlleva un mayor sentido de la comunicación. No hay una interpretación experta, sino que la interpretación interactiva del texto favorece el valor de cada una de las contribuciones.

En los espacios de debate elitistas se infravalora las aportaciones que una persona no académica pueda realizar, y ello desencanta el objetivo primordial del lenguaje, que es la comunicación. ¿Cómo pueden comunicarse si ya están infravalorando su capacidad de lenguaje? Las interacciones que en estos espacios se crean, son interacciones de poder, que limitan la libertad de comunicación de las personas.

De momento, solo los actos comunicativos dialógicos están mostrando crear realidades sociales transformadoras. El objetivo principal es la comunicación y el consenso de cómo se quiere seguir creando una realidad en concreto. En nuestro caso, cómo la agencia humana consensua debatir los textos literarios clásicos.

Cuantos más sujetos capaces de lenguaje dialoguen, discutan y comenten una obra, más viva estará dicha obra. El discurso crítico será mucho más enriquecedor y profundo al incluir las diferentes valoraciones sin jerarquías excluyentes. Tal y como argumentaba Bakhtin (1981) es a partir de la interpretación dialógica de los textos que podemos avanzar en un conocimiento más profundo de la obra. Sin esa dialogicidad no es posible.

Y así lo podemos comprobar también en la comunicación que realizó Galeano a la comisión de tertulias en el siguiente ejemplo.

Galeano al recibir una invitación al III Congreso de Tertulias Literarias Dialógicas celebrado en 
Madrid en el 2003, y tras conocer el proyecto de las tertulias literarias dialógicas, escribió a CONFAPEA la siguiente carta (Galeano, comunicación personal, noviembre 2003):

"Les explico esto para que ustedes confirmen, haciendo lo que hacen, que escribir no es una pasión inútil, y que esta tentativa de comunicación merece la pena. El libro se realiza en quien lo lee, y en él o ella se multiplica. Si no fuese por el lector, que da vida a la voz del escritor, el libro no sería más que una cosa muda, un objeto muerto. $Y$ estoy seguro que Onetti y Joyce están muy contentos de estar aquí, hablando con vosotros, vivos en las palabras que escribieron y en los libros que dejaron. Y aunque ninguno de los dos lo confesará, porqué son un par de tipos entrañables disfrazados de puerco espín, también estoy seguro que están muy contentos de comprobar que mentían. Os envío un abrazo y os deseo muy felices comuniones".

Galeano, a través de las palabras que dirige a los y las participantes de las tertulias literarias dialógicas, reafirma el sentido del lenguaje, y la lectura en concreto. De nada sirve escribir si no hay espacios de diálogo donde se discuta. De nada sirve hablar del lenguaje si se discrimina parte de la población respecto al propio acto comunicativo. El progreso y desarrollo lingüístico avanza más cuando se tiene en cuenta los factores que se han ido exponiendo en el artículo.

Los actos comunicativos dialógicos que generan los espacios de tertulias literarias dialógicas, incluyen una mayor capacidad crítica racional como también un mayor placer en la comunicación que se establece entre los diferentes participantes. Las conversaciones promueven el disfrutar del lenguaje como vía para comprender más profundamente el mundo, tener más autonomía y establecer relaciones más dialógicas tanto en el marco de la tertulia dialógica como fuera de ella.

En definitiva, partir de los actos comunicativos dialógicos favorece el marco idóneo para superar las limitaciones que mantiene el sistema en los sujetos y liberarse de las mismas. Promueven la creación de estructuras comunicativas más igualitarias que apliquen de nuevo el encanto y el placer de la comunicación entre las personas. En el caso concreto de las tertulias literarias dialógicas da a lugar a la interpretación interactiva de los textos. Esta práctica consigue sustituir las interacciones de poder que se dan en entornos académicos tradicionales, por interacciones dialógicas. Y con ello, se consigue una comunicación más libre y profunda entre los sujetos.

\section{REFERENCIAS BIBLIOGRÁFICAS}

Bakhtin, M. (1981). The dialogic imagination: Four essays. Austin: Univeristy of Texas Press. 
Bakhtin, M. (1986). Response to a question from the novy mir editorial staff. En C. Emerson \& M. Holquist (Eds.), Speech genres and other late essays (pp. 1). Austin: University of Texas.

Beck, U. (2006). La sociedad del riesgo: Hacia una nueva modernidad. Barcelona: Paidós.

Bourdieu, P. (2000). La distinción. Criterio y bases sociales del gusto. Madrid: Taurus.

Bourdieu, P. \& Mizraji, M. (1988). Cosas dichas. Buenos Aires: Gedisa.

Chomsky, N. (1985): Knowledge of language. Its nature. Origin and use. Nueva York: Praeger.

CREA (Centre of Research in Theories and Practices that Overcome Inequalities). (2006-2008). Actos comunicativos: Desigualdades en las relaciones de género. RD Project. Ministry of Education and Science. Spanish Government.

CREA. (2006-2011). University of Barcelona. INCLUD-ED. Strategies for inclusion and social cohesion from education in Europe. Integrated project, priority 7, Citizens and Governance in a Knowledge-based Society. 6th FP. European Commission.

Eco, U. (1979). Obra abierta. Barcelona: Ariel.

Eco, U. (1992). Los límites de la interpretación. Barcelona: Lumen.

Flecha, R. (2000). Sharing words: Theory and practice of dialogic learning. Landham, MD: Rowman \& Littlefield.

Flecha, R., Soler, M. \& Valls, R. (2008). Lectura dialógica: Interacción es que mejoran y aceleran la lectura. Revista Iberoamericana de Educación, 46, 71-87.

Searle, J. \& Soler, M. (2004). Lenguaje y ciencias sociales. Diálogo entre John Searle y CREA. Barcelona: El Roure.

Siguán, M. (2001). Redescubrimiento de la lectura. La Vanguardia, 15.

\section{NOTAS}

1 Reconocimiento de las tertulias literarias dialógicas. Disponible en: http://www.neskes.net/confapea/tertulias/reconocimiento.htm

2 Confederación de Federaciones y Asociaciones de Personas Participantes en Educación y Cultura Democráticas. Disponible en: http://www.neskes.net/confapea/tertulias.htm

3 Federación de Asociaciones Culturales y Educativas de Personas Adultas. Disponible en: http:// www. facepa.org/facepa 